\title{
Decision Making System for Regulation of a Bimodal Urban Transportation Network, Associating a Classical and a Multi-Agent Approaches
}

\author{
Karim BOUAMRANE \\ Computer Science Department, University of Oran, Algeria \\ LAMIH/SP, University of Valenciennes \\ 59300 Cedex 9, France \\ e-mail: karim.bouamrane@univ-valenciennes.fr \\ Christian TAHON, Marc SEVAUX \\ LAMIH/SP, University of Valenciennes \\ 59300 Cedex 9, France \\ e-mail: \{christian.tahon,marc.sevaux\}@univ-valenciennes.fr
}

Bouziane BELDJILALI

Computer Science Department, University of Oran

BP 1524 EL Mnaouer Oran, Algeria

e-mail: beldjilali@univ-oran.dz

Received: January 2005

\begin{abstract}
To offer high quality services, when users are increasingly demanding and competition more and more hard, is now a major problem that transportation companies are faced with. So, ensuring a regular traffic needs to identify the randomly occurring disturbances that affect the transportation system and to eliminate or reduce their impacts on the traffic.

This paper presents a decision support system TRSS (Traffic Regulation Support System). TRSS is a supervision environment for the regulation of urban transportation system. TRSS (tram and bus) is based on the regulation operator decision-making process. It provides the operator with the information he needs to identify disturbances and evaluate potential corrective actions to be carried out, according to the regulation strategy he has selected.

The first part of the paper presents the decision model we work with. The second part deals with the functional model used in the decision support system. Decision support system for transportation and characteristics of a DSS for a transportation system are described in the third part. In the fourth part, we present the components of the decision-making TRSS supervision tool. In the fifth part, we present the criteria of evaluation and the sixth part is devoted to the presentation of the results.
\end{abstract}

Key words: urban transportation system (UTS), regulation, decision support system, cognitive engineering, case-based reasoning (CBR). 


\section{Introduction}

The quality of service to the users of the systems of transport is an essential element of competitiveness for the haulage companies. It covers multiple aspects, in particular: comfort, safety, punctuality and the effective management of the incidents. The latter two aspects relate to the regulation of the traffic which must ensure the control of the disturbances appearing at the time of the exploitation of the transportation system. The regulation of the traffic is a complex task, where the decisions are made according to the state running of the transportation system. The owners of the network encounter many difficulties to maintain traffic in conformity with estimated planning (theoretical timetable) and to comply with the rules of use (rules of regulation, safety requirements, commercial role of the company...). The encountered difficulties are due for example to the bad conditions of circulation, staff shortage, breakdowns of material, desynchronisation between the various means of transport.

The installation of an Automatic Monitoring Vehicle (AVM) brought a sensitive help to the operators of regulation (regulators). The AVM allow the follow-up in real time the exploitation of an urban transportation system and treat very significant quantities of information relating to the network. But, in the event of disturbances, the regulators cannot take into account the whole of this information. It is thus necessary, to enable them to make effective decisions, to provide them relevant information. It is the role of Traffic Regulation Support System (TRSS) which, starting from the whole of the information provided by the AVM, must identify the disturbances which appear and propose and evaluate corrective actions. In addition, the TRSS is necessarily interactive, and must leave with the regulator control management of the disturbances and the choice of the corrective actions. The objective of our work is thus to propose a decision-making system for regulation, guiding the regulator in its step of diagnosis of the disturbances and development of actions of regulation. This objective led us, initially, to establish a model of the decision-making process of the regulator.

\section{Models of the Decision-Making Process of the Regulator}

\subsection{Context of Regulation}

Works undertaken in the field of the decision-making system for regulation of an urban transportation system are interested mainly in the development of algorithms of automatic regulation. Soulhi (2000) offers a contribution of artificial intelligence in decisionmaking in the management of public transportation system by using a fuzzy model. Balbo (2000), through a multi-agents architecture, is interested in planning of offer by readjusting supply in means of transport compared to real: confrontation of the theoretical state (theoretical timetable) and the true state (real timetables), the correspondences are not explicitly treated by. Laichour (2002), by adopting a multi-agents approach, offer to regulate correspondence only by using a limited number of actions of regulation. Chihaib (2002) uses a fuzzy approach for regulation to treat disturbances in interstations. Finally Fayech (2003) adopts a multi-agents approach integrating a genetic algorithm. One can 
note that this work approaches the resolution of regulation problems without taking into account their integration in an interactive environment necessary for the regulator.

Compared to PTV Vision (Visum, 2005), our project does not make in planning and the definition again route. Our TRSS uses theoretical planning (TM) and compares the values of the parameters received from the transportation system via the AVM in order to start on the request of the regulator for proposing an action of regulation. Our TRSS exploits actions of regulation employed by the company of transport (Semurval, 2004), which pushed us to implement the algorithms corresponding to these actions. These algorithms are generally inspired by Cure (1984). However, the implementation of these actions does not make it possible the regulator at the same time to build only one action of regulation. This situation, led us to reflect on the capitalisation of the know-how of the regulator by proposing a module containing case, then in order to enrich the environment of supervision with other algorithms of regulation, we have to integrate an evolutionary approach with an anytime algorithm (interruptible) (§4.3). This enabled us to propose with the regulator several solutions for the same disturbance. The advantage of this step is that we accompany each decision by an evaluation. This evaluation is done on the basis of number of criteria (§5) established with our partners of the Transport Company. These criteria characterise the evolution of the network and give a precise idea to the regulator so that it can choose its solution. It is necessary to add moreover, that we do not deal with simulation, our system TRSS integrates a module which was developed by Bonte (2004) which is given the responsibility of the complete simulation of the network to be controlled.

\subsection{Models of the Human Operator}

Three currents of modelling can be identified in literature (Boy, 2003). The current "human factor" during period 1940-1955, aims at the modelling of observable elements by the operators during the accomplishment of their tasks. They are then interested in the analysis of human activity (Fitts, 1964). In current "automatic human", period 19551980, the researchers lean on theories of physics to try to model the human operator. Different models represent this tendency, among which the theory of information (Sheridan, 1974), the model OCM "Optimal Control Model" (Sheridan, 1985) and the model of the regulation of human activity (Millot, 1988).

Finally, in actual current "cognitive engineering", the roles of human operators are rather tasks of supervision, including the decision-making. Technical problems concern then the decision-making for control, management production, and monitoring or diagnosis (Staroswiecki, 1998).

Trough the identification of the behavior of the regulator (Boumane, 2005), we are located in the cognitive engineering approach because of the quasi-total presence of the regulator as the final decision-maker at every step of the decision process. An adapted model for regulation inspired from Rasmussen and Hoc (Hoc, 1996) was presented in (Bouamrane, 2005). Fig. 1 represents the decisional behavior of the regulator. This figure shows the identification of this behavior in five phases: acquisition of the disturbances, analyzes and diagnosis, decision-making, evaluation and actions (implementation of the 


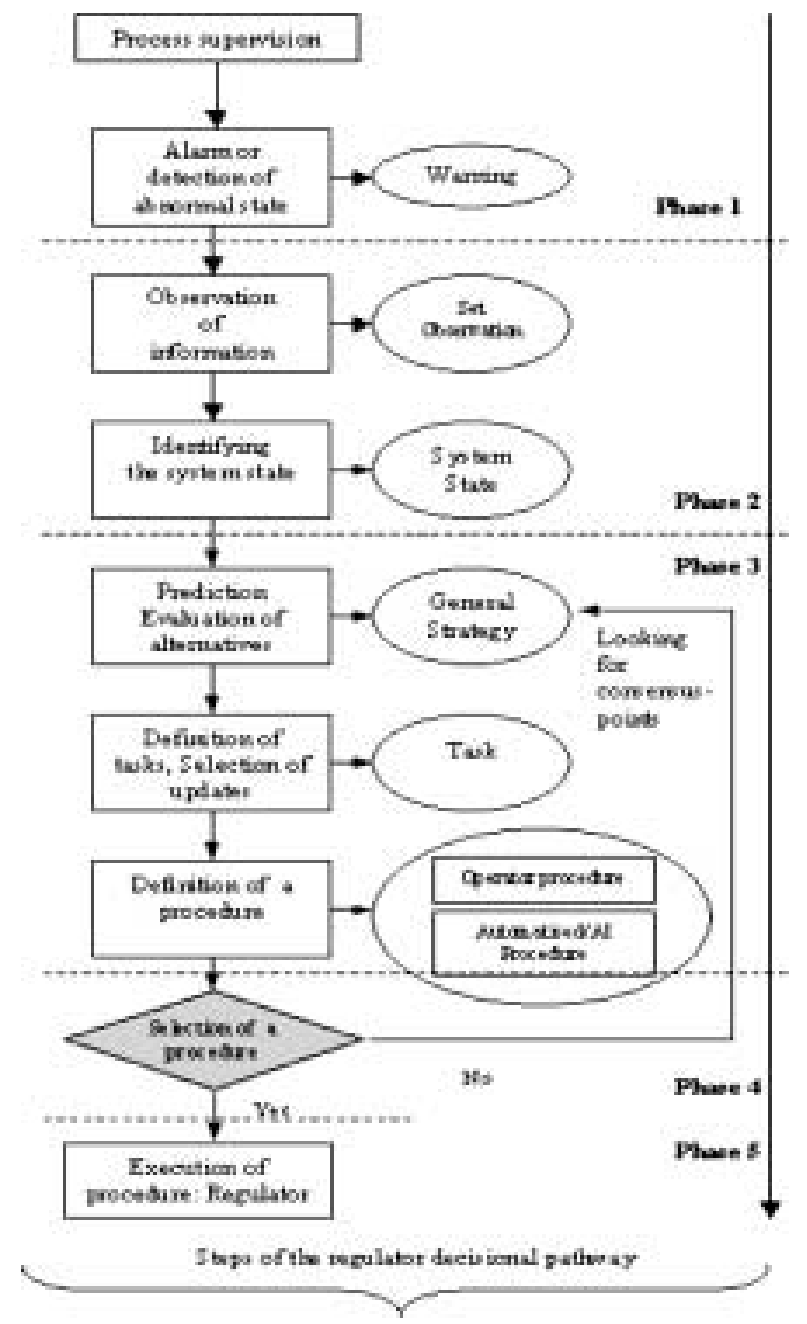

Fig. 1. Synthesis of the decisional pathway adapted to the regulator of an urban transportation system.

adopted solution). In the text that follows, we are particularly interested in the phase "decision-making" in which, we present the architecture and the operation of the modules proposed, while the evaluation phase which permit to us to evaluate each decision recommended to the regulator.

\section{Decision Support System for Transportation}

In order to realize the necessity of a DSS for transportation System. It is important to grasp the problems related to a real-time management of traffic. 


\subsection{Planning and Regulation Processes}

The planning process of a public transport company consists of first establishing different timetables that describes trips according to the lines, frequencies, transport demand and travel times in the network. These trips are then transformed into blocks and assigned to vehicles. A crew scheduling process finally follows this vehicle scheduling (Huisman, 2001). Hence, the vehicle schedules are fixed for every timetable period. This type of vehicle scheduling is in fact called predictive scheduling (Issai, 2001). It is based on a periodic review of demand and resource availability in order to create arrival and departure times for the vehicles at the different stops of the network. However, in reality, travel times and transport demand are not fixed because of random external influences that affect the traffic within the network and cause disturbances. Consequently, the theoretical schedules resulting from the planning process cannot be followed exactly, which compels trips to start late and thus, passengers to wait longer (Borne, 2002).

Therefore, to reduce the effects of the disturbances, the theoretical schedules have to be adapted to the traffic real conditions through regulation or rescheduling tasks. This process is then called reactive scheduling. It results in the creation of new schedules that increase the level of service (LOS) by undertaking operational decisions such as the injection of an extra vehicle in the network or the deviation of routes of some vehicle. Presently, it's a human operator, who performs these real time tasks and controls the global network traffic by treating the information provided by the AVM system and the vehicle drivers. The LOS can be represented by different regulation criteria such as the regularity, punctuality and connection criteria.

However, the regulator is usually overloaded with information, which complicates its decision making task. In addition, despite the AVM system assistance, the regulator spends more than $50 \%$ of his work time in communication with the vehicle drivers (Borne, 2002).

In order to take efficient decisions, it is necessary:

- to have a global vision about the network;

- to treat immediately the available information about the network state;

- to make a space-time analysis for disturbances;

- to project in the future the effect of the regulation actions on the network.

Hence, the regulator has to carry out difficult tasks that are often inaccessible at the human scale especially if many disturbances occur simultaneously, which involves the assistance of a Decision Support System.

\subsection{Characteristics of a DSS for a Transportation System}

As stated previously, a DSS has to start by problem recognition. The disturbances or the incidents represent the problems in UTS. In order to react as soon as possible against these problems, the DSS has to predict, if possible, in advance the disturbances. Otherwise, it has to detect them, identify and analyze them to evaluate their impact on the network (Fig. 1). Then, a proposal of decisions is communicated to the regulator that chooses the adequate measures to apply. 
The regulator got a lot of information from the AVM system, at the same time, in a limited time, he has to take instant decisions to resolve problems which can occur simultaneously. For this part of the decision support system, we propose a model for regulation based on a CBR approach that allows to treat the disturbances what frequently occurs in the same context. In addition, The regulator can reject the solution suggested by the CBR module and wish to control by itself. Within this framework, we propose to him a set of actions of regulation based on specific algorithms (mathematical models).

Furthermore, due to network information dispersion, as well as its distributed management and mobile telecommunication, a distributed model for such a system seems to be appropriate (Fayech, 2003; Gruer, 2001). Since Agent-based approaches have proven their efficiency in distributed artificial intelligence domain's applications. We present in this context the third model based on a multi-agent Decision Support System for UTS.

The use of the agent-based approach adds a good intelligence component to the system. The architecture of this system also has a high degree of multi-cooperation since the problem solving is based on a mutual adjustment of the solutions between the different agent of the system. In fact, the generation of decisions is undertaken by an agent based on an anytime algorithm. The success probability can be measured via the different regulation criteria on which the decision-making relies.

\section{The Components of the Module Decision-Making of the TRSS Supervision Tool}

The regulation environment is build like a manager of models (Fig. 2). The models exist within a same architecture and divide the same databases. Each model, when the regulator chooses it, proposes solutions based on the choice of the regulator. The proposed solutions

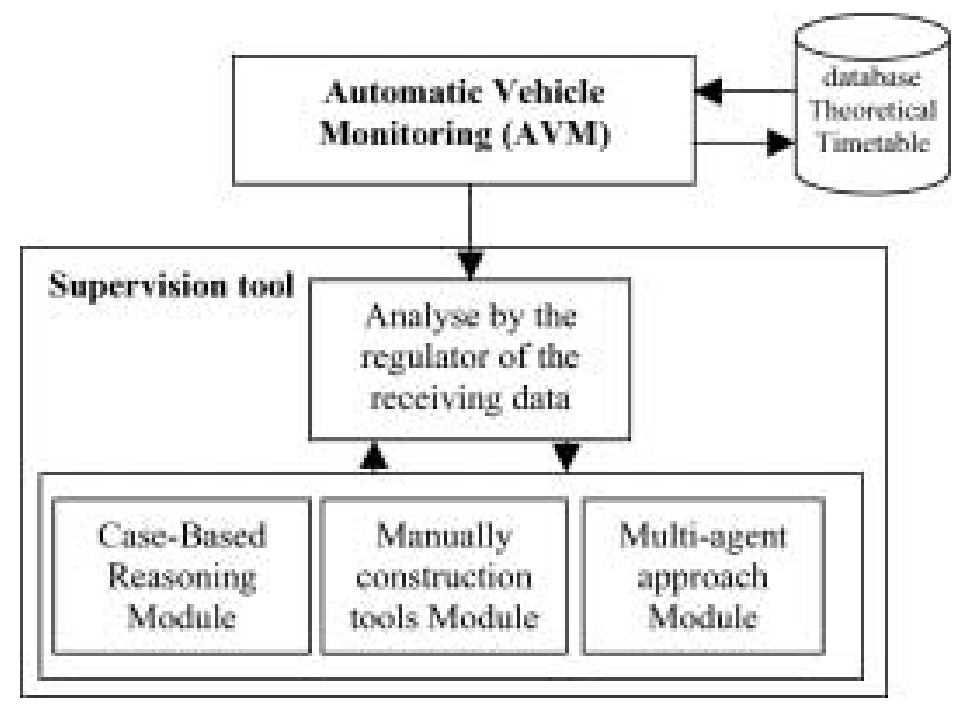

Fig. 2. Principals modules of the supervision tool. 
from each model of decision are evaluated and proposed to the regulator in order to choose the most appropriated one according to his experience.

This set of models is presented hierarchically to the regulator. The regulator could order:

1) a Based-Case Reasoning (BCR),

2) build his own solution manually with the held of a toolbox of regulation actions (classical algorithms of regulation) based on mathematical models,

3) an agent approach integrating anytime algorithm for regulation.

These decision-making modules could be selected according to the complexity of dysfunction. This complexity or difficulty is measured through a classification process with the help of parameters, which were measured, on the network and local parameters of traffic management. The list of parameters contains:

- the disturbed vehicle (bus or tram),

- the location of the dysfunction (geographical location),

- type of next stop and the distance between it and the dysfunction location,

- time of disturbance,

- estimated number of passengers on board of the disturbed vehicle,

- estimated Number of passengers waiting at the next stop,

- etc....

\subsection{Case-Based Reasoning (CBR)}

The first mode of reasoning is the reasoning based on cases. Its principle is based on a reasoning of "analogy" (Burstein, 1989; Mignot, 1997), where experiences from the past are used to define a solution for a present problem.

A present case composed by a disturbance, which has to be resolved, is taken by the AVM system or by Radiotelephone. This disturbance case is compared to former cases in the cases-base. A type of disturbance and its solution compose each one of them. The comparison is done by the calculation of a measure of similarity, weighted sum of local comparisons of different descriptions of the disturbance (step "find").

The cases with the highest scores for this measure are declared nearest neighbors and are selected to build a solution for the present disturbance (step "reuse"). This solution will be "reviewed" by the user and then added in the base of cases in order to be used again in a further step (step "keep") (Aamodt, 1995; Mille, 1997).

The execution of the cycle allows to create a knowledge base for the resolution of real problems and to reuse this knowledge to solve future disturbances. This reasoning is used by human beings in various environments and plays an important role in the expertise

\subsubsection{Presentation of the CBR Approach Used}

In our decision-making system for regulation, this module is containing a based-case reasoning organized in form of an indexed database. The disturbance which arrive are compared thanks to a partial order " $<$ " such as if $p b 1<p b 2$. We can say that the disturbance $p b 1$ is more specific than $p b 2$. With each recorded disturbance noted "source" is 
associated an index idx(source) such as $i d x$ (source) $>$ source: an index is a generalization of a disturbance source. The index is organized in a hierarchy Hidx for the order " $<$ ".

To remind a scenario (recorded disturbance) by the means of Hidx. We use two processes of classification. Ordinary or strong classification seeks the index of the source problems, which are more general than the target problem. More precisely, being given a target problem, our CBR seeks a disturbance source such as idx(source) $>$ target. The source $<$ idx (source) is a strong classification characterized by the equation

$$
\text { Source }<\text { idx }(\text { source })>\text { target } \text {. }
$$

In the event of failure of strong classification, when there is not treated disturbance source such as $i d x$ (source) $>$ target, smooth classification is activated. The latter is based on a "approximate" pairing. That is to say that the CBR module seek functions of modification $\varphi$ and $\Psi$ such as

$$
\text { Source }<\text { idx }(\text { source }) \cong \varphi(\text { idx }(\text { source }))>\Psi(\text { target }) \cong \text { target },
$$

where $\cong$ is read "similar to" and means intuitively "equal to modification near". The function of modification $\varphi$ check the following property: if a treatment(idx(source) is known, then we can build a treatment $(\varphi($ idx $($ source $)))$. Unlike, the function of modification $\Psi$ is such as, if a treatment $(\Psi($ target $))$ is known, then a treatment (target) can be built.

The remind in the CBR model seeks a similar treatment to the target disturbance and establishes how they are similar. source is similar to target if one of the sequences of relations (1) and (2) between source and target is checked. These sequences of relation's (1) and (2) are called "ways of similarity". The measure of similarity in our case is based on six data:

- location:

- name of the nearest stop where the dysfunction is located,

- distance to the next stop,

- distance to the next terminus;

- the day time (high traffic, low..);

- load of the vehicle (low, average, maximum);

- mode of transportation (bus or tramway).

Given a target disturbance, the case source nearest to target is highlighted with a distance. This distance is based on a cost function which, with a way of similarity $\operatorname{Sim}($ source, target), associates a numerical value $\operatorname{cost}(\operatorname{Sim}($ source, target $))$. Given two disturbances source and target, the distance from source to target is defined by:

$$
d(\text { source }, \text { target })=\min \{\operatorname{cost}(\operatorname{Sim}(\text { source }, \text { target }))\} .
$$

The minimum being taken on the whole of the ways of similarity Sim(source, targets) from source to target. This distance is similar to an edition distance (Bunke, 1994). 
In other side, any disturbance, which not the solution is in the case-base, could not be solved. Where the recourse to the two other modules, either a manual construction of the solution (mathematical model), or an automatic regulation (multi-agent approach).

\subsubsection{Why a CBR Approach?}

The principal objective of our system of regulation, which is based on a CBR approach, is to propose to the regulator in a tiny time a solution nearest possible to the disturbance in progress. This is so that it could be discharged from this task given that it passes more than $50 \%$ of time with the radiotelephone. This approach is applicable insofar as the consultation of the incident sheets carried out by the services of the maintenance and regulation raises thousands of incidents per year, whose majority is similar, as much on the context that on the strategies applied to solve them.

The CBR module has utility only insofar as there are solutions in the database. These solutions are built by the regulator in a manual way or proposed by the agent approach (automatic generation of solutions). The two approaches will be presented in the continuation. The database of the module CBR is enriched through the actions of regulation composed manually by the regulator or automatically generated by the anytime algorithm anytime. The database represents the capitalization of the know-how of the regulator, being given that even the solution suggested by the anytime approach is validated or rejected by him.

\subsection{Building the Decision Manually}

The regulator can choose to build his own regulation strategy. In this case the regulation could be online for one line at once. This line could be a tramway line or a bus line. For this, the environment of decision-making proposes different tools.

\subsubsection{Approach of Temporal Sequentialisation (Tram)}

The basic principle is to establish mathematical models, linear or not, to characterize the transfer between two successive stops of a traffic line with high density.

Two types of equations are established: the equations with deviations and the equations with intervals (Soulhi, 2000) obeying to the following reasoning, in the case of a linear modeling:

- determination of the starting moment of the vehicle $(i)$ of the quay $(k+1)$ :

$$
t_{k+1}^{i}=t_{k}^{i}+r_{k}^{i}+s_{k+1}^{i}
$$

with $t_{k+1}^{i}$ - starting moment of the vehicle $(i)$ of the quay $(k)$,

$r_{k}^{i}$ - time of course of the vehicle $(i)$ between the quays $(k)$ and $(k+1)$,

$s_{k+1}^{i}-$ time of stop at the station $(k+1)$;

- determination of the time of course between the quays $(k)$ and $(k+1)$ :

$$
r_{k}^{i}=R_{k}+u_{k}^{i}+W_{l k}^{i}
$$


with $R_{k}$ - time of nominal course enters the quays $(k)$ and $(k+1)$, $u_{k}^{i}$-action of the order applied to the vehicle $(i)$ between the quays $(k)$ and $(k+1)$, $W_{l k}^{i}$ - time of error of modeling.

Modeling is based on the following assumptions:

- the time of parking to quay varies linearly with the number of passengers to embark in the vehicle;

- the number of passengers to be embarked is proportional to the interval separating two successive departures from the same quay;

- the characteristics of modeling are stationary over the period considered.

These assumptions enable us to determine the downtime (Stop time) of the vehicle $(i)$ on the level of the station $(k+1)$ :

$$
S_{k+1}^{i}=C_{k+1}\left(t_{k+1}^{i}+t_{k}^{i}\right)+D_{k+1}+W_{2 k}^{i}
$$

with $C_{k+1}$ - factor of proportionality binding the number of passengers to be embarked with the interval of time between two departures,

$D_{k+1}$ - minimal downtime to the quay $(k+1)$,

$W_{2 k}^{i}$ - time of error of modeling.

\subsubsection{Algorithm of Regulation}

The definite algorithms of regulation relate to the established models and have for principal objectives:

- a regulation on schedule: the theoretical hour must be respected as well as possible,

- a regulation on interval: keeping a constant interval between the various successive trams,

- a mixed regulation on schedule and intervals.

This model is an ideal model based on a certain number of assumptions. However, under disturbed operation, these assumptions can prove to be false, from where interest to resort to other models.

\subsubsection{Critical of the Approach of Temporal Sequentialisation}

This method of regulation presents for principal advantages:

- to allow a sufficiently detailed simulation of the traffic ensuring a conformity of the moments of passages quay without being concerned with the state of a tram between two quays;

- to allow the construction of relatively effective laws of order, requiring only one limited information collected at the time of the passages to quay only; where are a reduced cost for the acquisition of information.

Nevertheless, some limit appear:

- no direct connection established explicitly between the order calculated and their effects on the modification of the values kinematics of the trams;

- the validity of the results obtained is extremely dependent on various estimated parameters. The difficulty to obtain reliable estimators can influence the validity of the final results obtained; 
- the disturbances can be treated only in the level of the quays, whereas a reaction at the time of their detection would be more effective.

\subsubsection{Regulation Actions for Buses}

The regulator can also control other regulation actions for buses following the specification of the location of the dysfunction (connection or inter-station) (Fig. 3).

We suggest following regulation actions used by our partner (Semurval, 2004):

- Top the foot off line: put except service of a vehicle on a course or part of course which borrows a faster route regular in order to compensate for its delay off line and to take again the service with the next terminus or an unspecified stop on the line.

- Direct on line: the vehicle follows the itinerary of the line ensuring only the stops of descent for the passengers on board.

- Half-turn on line: remove of a part of the course to give the vehicle on its theoretical schedule, at a point of reversal, following a significant delay of this car.

- Half-turn with exchange of drivers and vehicles: the late vehicle is caught by the vehicle following charged but at the hour. The vehicle at the hour transships its customers on the late car and exchange of driver. Then, the late vehicle continues the service on the schedule of the vehicle at the hour. This lasts half-turn and takes the theoretical schedule of the late car.

- Going beyond and service in descent only: the following vehicle at the hour catches up the late vehicle. The second vehicle passes in front of the first and ensures the service normally. The exceeded vehicle continues the race but ensures only the stops of descent.

- Departure delayed with the terminus: if a vehicle having a delay higher than its time of beat to the terminus of arrival, one delays the preceding vehicle with the terminus of arrival of half of the value of the real delay.

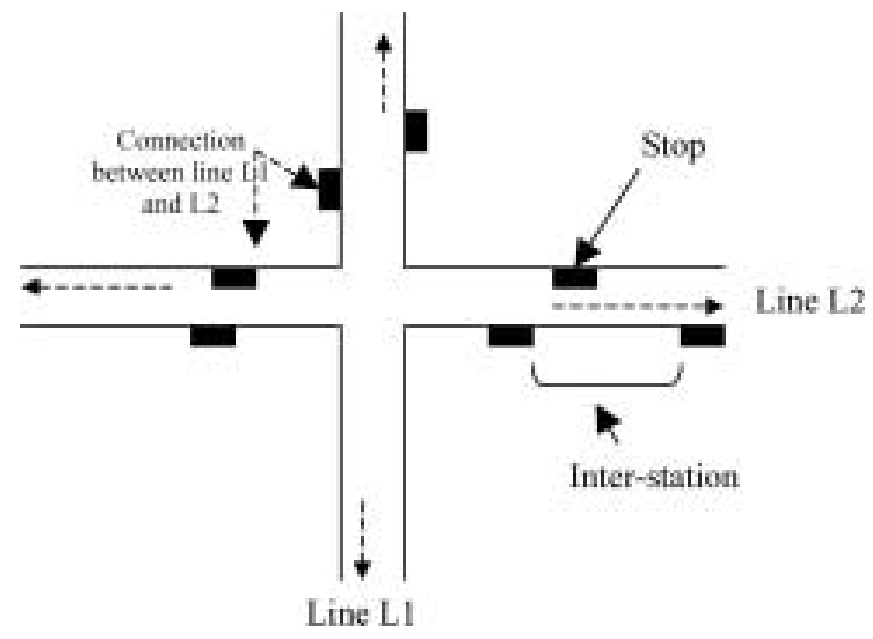

Fig. 3. The different localization in a transportation network. 
- Exchange of the drivers and the vehicles: a late vehicle is caught by the vehicle which follows it, then, one carries out a transshipment of passengers of the second vehicle on the first vehicle which is charged. One exchanges then, the drivers and the numbers of vehicles. The second vehicle, which is empty, sets out again high the foot.

- Handing-over per hour by reserve and available: inject a vehicle and a driver on the theoretical schedule of a vehicle that is late or broken down.

- Regulation in terminus: carry out departures advanced or delayed on a terminus to restore the regularity of the line.

- Regulation on line: delay proportionally two or three vehicles upstream and downstream from a late vehicle to avoid the overload on this one and to help it to not increase its delay in order to restore the regularity.

The whole set of actions is combined to the set of changing and creating missions. The corresponded algorithm are available in (Cure, 1984). The choice of actions done by the regulator could systematically be evaluated with defined criteria.

\subsection{Multi-Agent Approach with Evolutionary Regulation Algorithm}

\subsubsection{Why Multi Agent Approach?}

The distributed and opened character of the urban transportation network and the complexity of executing tasks, need a modular decomposition of the considered problem. The using of the multi-agent paradigm implies the integration of mechanisms, which take into account the temporal dimension. On the other hand, as we saw the advantage and disadvantage of the precedent methods in the treatment of the regulation, we choose a method which is based on an anytime algorithm which allow the conception of complex applications in real time and which results get better when the allocated time increases.

\subsubsection{A Real Time System and Multi-Agent Approach}

The system we propose is composed of agents who have evolutionary reasoning techniques. The agents adapt constantly the quality of collective's solutions they propose to the resources. These agents are in a dynamic and uncertain environment and they have to share the resources and tasks to get an optimal realization. Our system can predict any behavior related to the environment with which it interacts to give real guaranties concerning the respect of the temporal expiration dates.

For that, the recourse to the anytime technique seems a promising solution. The multiagents system in our work must acquire a behavior anytime. The acquisition of this behavior must be done in two levels:

- the local level: It's the agent level, where the agent will have a behavior anytime;

- the total level: It's the multi-agent level, where the system behaves a anytime comportment.

\subsubsection{A Distributed Decision-Making System}

In our multi-agent system, the agents who form the software system have at the same time an anytime behaviors and the capacities of functioning in distributed mode. The characteristics, which are presented by these agents, are following: 
- an anytime behavior;

- an automata (ATN) allows to model the stopping point of the anytime algorithm;

- a clock to measure the time between the states of the automata;

- communication functions allowing:

- the communication between the anytime agents of the horizon $H$,

- the communication between agents of temporal coordination. This means between two horizons $H$ and $H^{\prime}$;

- temporal discretisation function;

- a time prediction function.

In the decision-making system the anytime properties will be used for a progressive extracting of information. At the beginning of the extracting process we will have superficial, common and less precise information. The further we go in time the extracted information will be precise and important.

4.3.3.1. What is an Anytime Behavior?

An anytime agent is an agent with an anytime algorithm and which will be able to:

- give intermediate results of increasing quality at each execution step,

- predict the needed time to obtain the next intermediate result.

\subsubsection{Temporal Discretisation Function}

The aim of this function is to find a time unit, which could be used to measure the expired time between two states of ATN, and is greater than the base time unit. The $d_{i, i+1}$ is the transition between two states $i$ and $i+1$ and delta $T$ is a variable which represents a subdivision of time and $n_{i, i+1}$ the number of delta $T$ subdivided between two states $i$ et $i+1$. We have the following relation:

$$
d_{i, i+1}=\operatorname{delta} T * n_{i, i+1}, \quad \text { where } i=1,2,3 \ldots \Rightarrow \operatorname{delta} T=d_{i, i+1} / n_{i, i+1} .
$$

\subsubsection{Time Prediction Function}

This function allows to predict the running time needed to get over to the next state of ATN from the current state. This estimation is done in relationship of the discrete running time needed usually to get over to the state to reach.

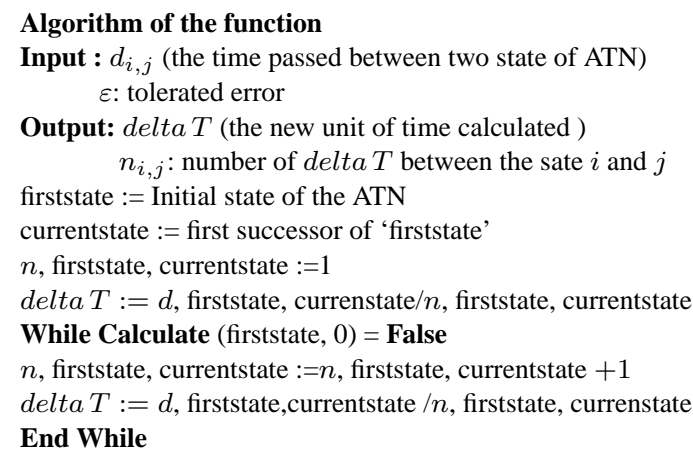




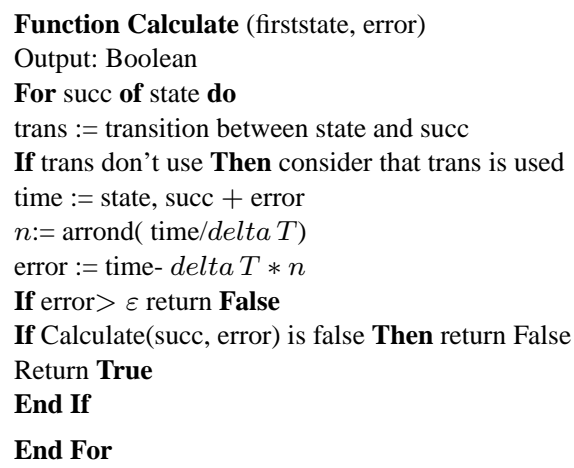

\subsubsection{Application of the Model on the Urban Transportation Networks (Process of Detection of a Disturbance)}

Our aim is to apply this approach on a bimodal urban traffic network to help the regulator to take a decision in case of disturbance in the normal functioning of the network.

\subsubsection{Take into Account the Dynamic of the Disturbance}

The taking into account of the consequences of a disturbance initiate the constitution of new sets of information in function of the vehicle expected by the concerned stops.

We are defining three subsets:

- the waiting stops of the delayed vehicle,

- the waiting stops of the vehicle following the vehicle which is late,

- the vehicle preceding the delayed vehicle.

The situation of the network changes in function of the evolution of the state of the delayed vehicle and this following two axis:

- The time: If initially the vehicle is delayed during one of its stops, the number of points changes in function of the evolution of this delay.

- Space: The number of stops concerned by the problem changes also in function of the movements of the vehicle.

\subsubsection{Space Time Horizon}

The regulation process operates only in the disturbed mode. It is necessary to define through the diagnostic phase the set of the entities of the network, which are related to the considered disturbances or which could be involved in the decision phase. The definition of that kind of set depends on:

- the moment of detection of the incident,

- the nature of perturbations,

- the position of the different vehicles in the network at the moment ' $t$ ',

- the impact of the incidents,

- the configuration of the network,

- the nature of the involved vehicles,

- the period of the day etc. 
During a disturbance, a set of entities of the network is implied in this one (vehicles and stops). To take them into account, we establishes a horizon of regulation corresponding to:

- a space axis: represented by the stops intervening in the disturbance or the regulation;

- a temporal axis: represented by the participant in the disturbance or the regulation.

We represent the set of the stop by $S^{H}$ (stops of horizon $H$ ) and $V^{H}$ (vehicles of horizon $H$ ).

\subsubsection{Architecture of the Proposed Multi-Agent Model}

For the construction of our agents (Fig. 4) (Bouamrane, 2004) we get inspired from the work of (Balbo, 2000; Fayech, 2003; Laichour, 2002). But, we propose the same vehicle agent who supports bus and trams. We make a difference between the stop agent that treats the interstation disturbances and we defined a special agent for the management of connections. The present proposed model is consists of two modules:

- the surveillance module which is responsible of the management of the static time of the network,

- the regulation module which is responsible to manage the disturbances and the generation of the appropriate rescheduling measures (DTT).

The surveillance model works under normal and disturbed conditions: it is composed of following agents VEHICLE, STOP and CONNECTION. The regulation module treats the disturbances concerning the modes: buses and trams. The regulation module works

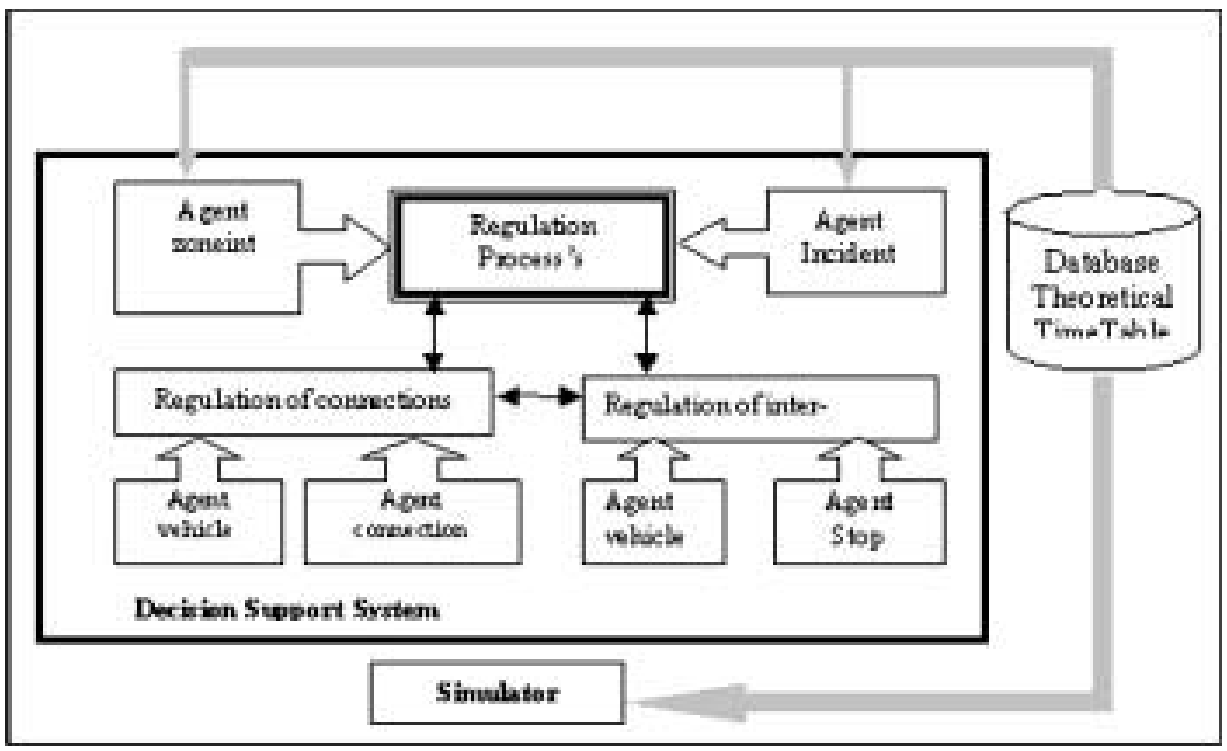

Fig. 4. Multi-agent system architecture. 
only in disturbed mode. It is created when a disturbance appears. The agents who compose it are INCIDENT and ZONEINT.

The two modules communicate with each other in order to cooperate in the real-time treatment of different incidents.

\subsubsection{Behavior of the Different Agents}

\subsubsection{Agent VEHICLE}

The role of a vehicle agent is:

- applying the Timetable (TT) which concerns him,

- applying the regulations measures assigned to it from the regulator.

The agent VEHICLE has only a reduced language protocol. When they are asked for the give information about there position, an estimation of arrival times or possible delays. These last two data are evaluated through a "moving" method.

An estimated arriving time of a vehicle at a station is given by AVM system but may be evaluated by:

- the distance between the stops,

- the average speed of the vehicle,

- a fluidity coefficient describing the state of the traffic,

- the departure time of the previous stop.

\subsubsection{Agent STOP}

The stop agents have following roles:

- make sure that TT is respected,

- detecting the interval between the theoretical times of transition and the real times,

- creating an INCIDENT agent to manage the disturbance,

- signal possible disturbances at stops,

- communicate with other STOP and VEHICLE agents to know about transition times.

In fact, STOP agents watch the transitions of vehicles to detect possible intervals between real or estimated times of transition and those of theoretical transitions. If the tolerated limit of the intervals, fixed by the regulator, is exceeded, these agents have to signal the appearance of a disturbance by creating an agent INCIDENT, which has the responsibility to manage it.

\subsubsection{Agent CONNECTION}

The role of an agent CONNECTION is the same as the one of a stop agent and its functions:

- management of connections,

- detection and determination of some decision to avoid missed connections,

- communication with other connections agents.

\subsubsection{Agent INCIDENT}

An agent STOP creates an agent INCIDENT when a disturbance caused by a vehicle appears. Being responsible for the considered disturbance, this agent first identifies its characteristics (disturbed vehicle, delay, stop, cause, ...). Then, it creates an agent ZONEINT 
(zone affected by the regulation) that will generate several possible rescheduling solutions through an evolutionary approach.

The agents INCIDENT have as roles:

- to create zoneint: for the diagnosis of the incident and the proposal for intermediate solutions,

- to await the primary diagnosis and solutions,

- to evaluate the diagnosis,

- to await solution regulation,

- to evaluate regulation,

- to propose regulation,

- to await validation from regulator,

- to apply and follow regulation.

The agents INCIDENT must at any moment provide to the regulator one or more solutions. Thus, a limiting duration of processing data can be fixed in order to provide as fast as possible the assistance to the regulator even by means of temporary but immediate solutions.

\subsubsection{Agent ZONEINT}

This agent is created by INCIDENT. It operates by an anytime-evolutionary regulation approach that takes into account the several rescheduling criteria. This agent considers the present decision making problem as a dynamic vehicle scheduling problem. Thus, the real time vehicle routing and scheduling problem is inadequate to solve with classical methods (Huisman, 2001; Thangiah, 1995; Zhu, 2000). For this reason, we choice an evolutionary algorithm for the rescheduling of the traffic through a partial network reconfiguration.

The actions which agent's ZONEINT carry out are:

- localisation of the horizon: the research of the zone concerned with the disturbance according to a strategy defined to build the space-time horizon;

- simulate TT: collect information necessary to the assistance of agents VEHICLE and STOP to estimate the schedules of passage in the disturbed state of the network (without regulation), forming the Disturbed TimeTable (DTT). The PTT hold account then possible delay or advances of the vehicles;

- control connection: to check the good course of the possible connections. If one or more connections are implied, it is necessary to rebuild the agents formed by ZONEINT in order to take account of the other lines concerned in the network;

- diagnose incident: evaluation of the importance of the disturbance according to the corresponding criteria of regulation;

- propose results: sending the various information collected to the agent INCIDENT.

Thus, we consider that the agents stop and the agent VEHICLE are anytime agents and the agents ZONEINT and agent CONNECTION are temporal coordination agent. 


\section{Evaluation Phase}

\subsection{Interest of the Evaluation}

The interest is apparent, particularly when the TRSS proposes several solutions to the regulator. In this case, the regulator was helped by the evaluation according to its objectives in the choice of the final decision.

\subsection{Selected Criteria}

To fill the objectives of the transport company to knowing: to minimize the latency of the passengers and the duration of the correspondences, five criteria were retained: profit in regularity, profit in punctuality, profit in correspondences (connection-node), satisfaction of the passengers and cost of the adopted solution. The first three criteria are well described in (Fayech, 2003), as for both others, we propose here a formulation according to the objectives of the transport company and relative so that we found in the literature (Certu, 1997). The description of these criteria will make it possible to better apprehend the objectives of this paper.

\subsubsection{Regularity}

This criterion corresponds to the regularity of the intervals of times which separate the successive passages from the vehicles at the same station. It relates to the minimisation of waiting of the customers to the stops of the network.

$$
\begin{aligned}
\mathbf{A T} & =\sum_{S_{j}^{m} \in S^{H}} \text { waiting }\left(S_{j}^{m}\right), \\
A T & =\sum_{S_{j}^{m} \in S^{H}} \sum_{V_{i}^{l} \in V^{H}}\left(a_{i j}^{l m} \times \sum_{S_{k}^{r}>S_{j}^{m}} \text { waiting }\left(t a_{i^{\prime} j}^{l^{\prime} m}-t d_{i j}^{l m}, S_{j}^{m}, S_{k}^{r}\right)\right)
\end{aligned}
$$

with

$$
\forall V_{i}^{l} \in V^{H}, \quad V_{i^{\prime}}^{l^{\prime}}=V e h^{+}\left(V_{i}^{l}, S_{j}^{m}, S_{k}^{r}\right)
$$

and $S_{k}^{r}>S_{j}^{m}$ represents the stops $S_{k}^{r} \in S^{H}$ included in itinerary of $V_{i}^{l}$.

\subsubsection{The Punctuality}

Punctuality is associated to the respect of the schedules of passage and thus of the duration of course. It is a question of optimising the total duration of the ways aboard various vehicles according to loads' of the latter (a number of customers). While considering, $S_{j^{\prime}}^{m^{\prime}}=\operatorname{Precedent} \operatorname{stop}\left(V_{i}^{l}, S_{j}^{m}\right)$ for $V_{i}^{l} \in V^{H}$ et $S_{j}^{m} \in S^{H}$

$$
\text { Total duration of the ways }=\mathbf{T D}=\sum_{V_{i^{\prime}}^{l^{\prime} \in V^{H}}} \sum_{S_{k}^{r}>S_{m}^{j}} a_{i j}^{l m} \times C_{i j^{\prime}}^{l m^{\prime}} \times\left(t d_{i j}^{l m}-t d_{i j^{\prime}}^{l m^{\prime}}\right) .
$$




\subsubsection{Correspondence}

To identify the occurrence of the correspondences, a variable $y_{i i^{\prime} j}^{l l^{\prime} m}$ is definite as equal to 1 if a correspondence is possible of $V_{i}^{l}$ to $V_{i^{\prime}}^{l^{\prime}}$ in the stop $S_{j}^{m}$ and 0 if not.

$\forall V_{i}^{l}, V_{i^{\prime}}^{l^{\prime}} \in V^{H}$, if at least one of the vehicles does not pass by $S_{j}^{m}$, then no correspondence is possible between them. In other words, if $\left(a_{i j}^{l m}=0\right)$ and $\left(a_{i^{\prime} j}^{l^{\prime} m}=0\right)$, then, $\left(y_{i i^{\prime} j}^{l l^{\prime} m}=0\right)$ et $\left(y_{i^{\prime} i j}^{l^{\prime} l m}=0\right)$

$$
\mathbf{T T}=\sum_{V_{i}^{l} \in V^{H}} \sum_{V_{i^{\prime}}^{l^{\prime} \in V^{H}}} \sum_{S_{j}^{m} \in S^{H}} y_{i i^{\prime} j}^{l l^{\prime} m} \times \omega_{i i^{\prime} j}^{l l^{\prime} m} \times\left(t d_{i^{\prime} j}^{l^{\prime} m}-t a_{i j}^{l m}\right),
$$

$\omega_{i i^{\prime} j}^{l l^{\prime} m}$ - number of passengers in correspondence from $V_{i}^{l}$ to $V_{i^{\prime}}^{l^{\prime}}$ in the stop $S_{j}^{m}$.

\subsubsection{Satisfaction of the Passengers (SP) or Quality of Service (QS)}

It is a function of the number of passengers on standby, the duration of their waiting beyond the estimated schedules, of the transhipment or not of these passengers as well as theirs safety during its transhipments or during the schedules of beginning and end of day:

- a number of passengers on standby: NBV,

- duration of waiting to a stop: $\Delta t=t a_{i^{\prime} j}^{l^{\prime} m}-t d_{i j}^{l m}$,

- transhipment numbers: NBT,

- safety coefficient (SC) expressed according to the period of the day, and the section of the network concerned:

$$
\left.S P=\sum_{V_{i}^{l} \text { avec }}^{N} \sum_{i=1} \Delta t \times \mathrm{NBV}\right)+(\mathrm{NBT} \times \mathrm{CS}) .
$$

\subsubsection{Cost of the Adopted Solution}

The commercial cost (CC) is expressed in function, of the number of used vehicles, the number of drivers requested in overtime as well as traversed mileage.

By considering that it:

- vehicle number is expressed by $\sum V_{i}^{l}$,

- drivers number by $\sum C_{i}^{l}$,

- overtime number $\sum$ supphours,

$$
\mathbf{C C}=\sum_{I=1, \ldots, n} V_{i}^{l} \sum_{I=1, \ldots, n} C_{i}^{l} \sum_{I=1, \ldots, n} \text { supphours. }
$$

\section{Simulation Results}

We consider a partial network of Oran City (North of Algeria), it is the network of the university zone (Fig. 5) because it is a zone where momentary flow is very significant and or the network comprises different points of connections. The various components of the network are the vehicles (buses and trams), lines, and stops. Characteristics of the network are shown in Table 1 and Table 2. 


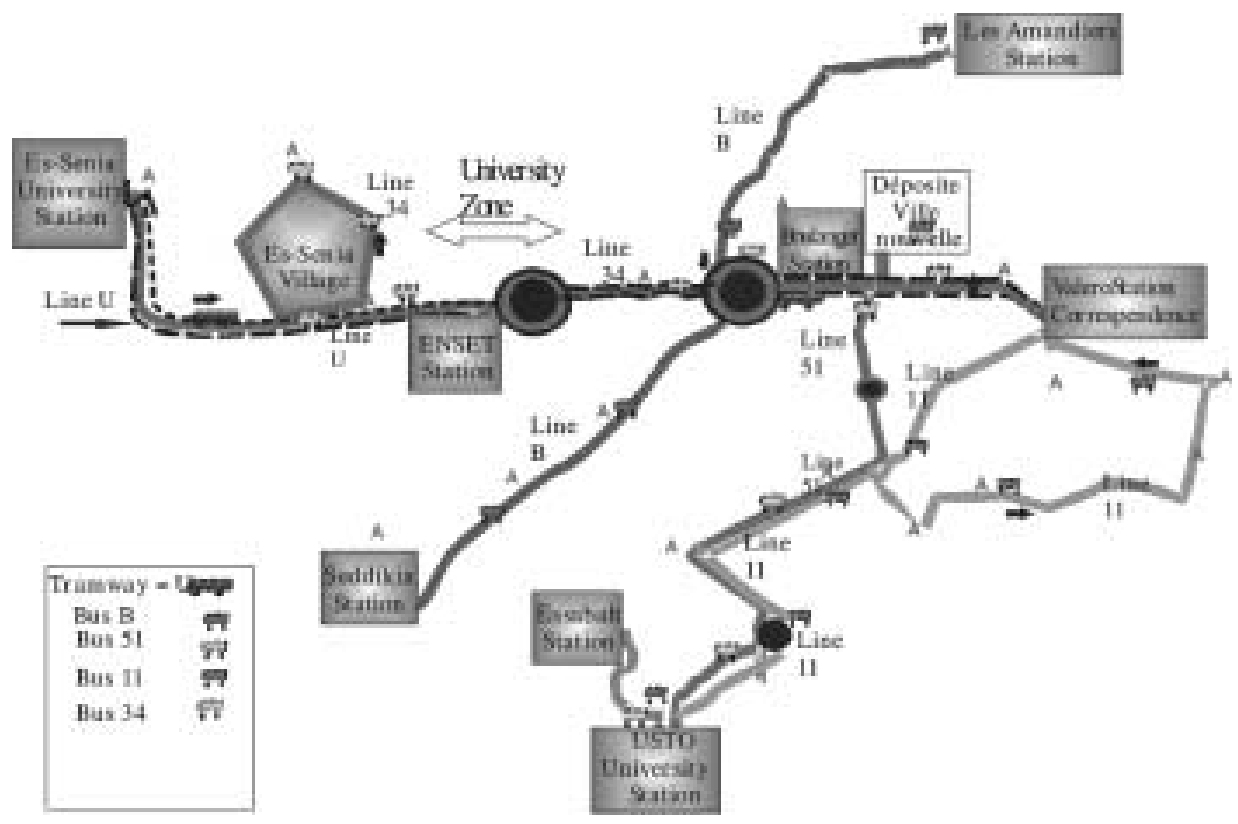

Fig. 5. Partial urban transportation network of Oran city.

Table 1

Characteristics of lines

\begin{tabular}{lccccc}
\hline & Line B & Line 11 & Line 34 & Line 51 & Line U (tram) \\
\hline Stop number & 20 & 20 & 10 & 12 & 13 \\
\hline Frequency & $15 \mathrm{~min}$ & $10 \mathrm{~min}$ & $20 \mathrm{~min}$ & $10 \mathrm{~min}$ & $5 \mathrm{~min}$ \\
\hline
\end{tabular}

Table 2

Connections between lines

\begin{tabular}{|c|c|c|c|c|c|}
\hline Connections & Line B & Line 51 & Line 34 & Line 11 & Line $\mathrm{U}$ (tram) \\
\hline Line B & & & $\begin{array}{l}\text { Carrefour } \\
\text { Boulanger }\end{array}$ & & $\begin{array}{l}\text { Carrefour } \\
\text { Boulanger }\end{array}$ \\
\hline Line 11 & & & & & Place Valéro \\
\hline Line 34 & & $\begin{array}{l}\text { Carrefour } \\
\text { Boulanger }\end{array}$ & & & \\
\hline Line 51 & & & Cité Hayat & & Cité Hayat \\
\hline Line U (tram) & $\begin{array}{l}\text { Carrefour } \\
\text { Boulanger }\end{array}$ & & & Place Valéro & \\
\hline
\end{tabular}




\section{Example of Scenario}

We consider two lines of the network L1et L2, which crosses on the level of a node of connection, vehicle 2 of the line 1 " $V_{2}^{1}$ " meets an unforeseen congestion in circulation and its driver estimates a delay of $7 \mathrm{~min}$ with the next stop. This disturbance can generate the following risks:

- miss the connections on the level of the node of connections,

- lost at least a revolution on the line.

\section{1) Application of the decision-making process}

The TRSS operate according to the following steps:

Step 1. Detect disturbance.

Step 2. Analyze the disturbance according to the TT.

Step 3. Select case:

Case 1: CBR module,

Case 2: mathematical module,

Case 3: multi-agent module.

\section{End case}

Step 4. Return to Step 1.

This delay is captured by the AVM (Step 1). From there a complement of information is shown to the regulator to inform it about the context of the disturbance (Step 2).

a) If the disturbance is a case already present (Step 3, Case 1), the supervisor tools reference to the regulator the solution suggested directly using the databases constructing with the CBR approach or improved with solutions constructing manually by the regulator. We consider in our example, that this disturbance has no equivalent in the database of the CBR.

b) Else if the regulator is not satisfied with the solution suggested, he can proceed to a manual construction (Step 3, Case 2) of his own strategy of regulation by using different actions (\$5.2.2) that use algorithm based on a mathematical model for regulation (Cure, 1984).

In our case, the choice of the regulator is made on "Direct on line". The vehicle $V_{2}^{1}$ follows the itinerary of the line L1 ensuring only the stops of descent for the passengers on board. The choice carried out by the regulator in manual construction is based exclusively on its know-how and the capacity to control the network which it under his responsibility. This choice is justified by the fact that the bus must imperatively make up for its lost time not to miss the correspondence. There can be in manual construction only one solution, that under consideration by the regulator. The environment of supervision proposes to the regulator the list of regulation actions. All the instructions which it gave before by telephone or radiotelephone are proposed to it through the environment of supervision with the corresponding parameter settings. Thus, we keep trace of all that it does like actions of regulation. What enables us on a side to enrich the base by case and another side to follow the work of the regulator for a possible evaluation of this latter. 
c) Else the regulator can choose to use the multi-agent approach (Step 3, Case 3). In this case the agent vehicle directly captures the delay and sends this estimate delay to nearest agent STOP " $A_{2}^{1}$ ", which starts the creation of the agent INCIDENT.

In its turn the agent INCIDENT creates the agent ZONEINT in order to form a group of agents (VEHICLE and STOP) concerned with this disturbance, these agents can be group togheter according to their lines or routes, or according to incidents which connect them (Space-time Horizon $\mathrm{H}$ ).

The agent ZONEINT locates the zone by taking of account the vehicles of the line L2, and communicates with all the agents concerned for extracting all information (the positions, their load, ...), and return to the agent INCIDENT a synthesis of the current situation. The agent ZONEINT has the following steps:

- it compares the theoretical value with that envisaged and observed,

- calculate the new disturbed timetable as well as the loads disturbed for the vehicles on the whole of the network,

- evaluates the consequences of the disturbance,

- following the choice of the mode, it would be necessary to define the law of deceleration/acceleration.

Once this stage carried out we estimate for each action a satisfaction degree, it is calculated while being based on the duration to find the normal mode. The choice of the action to be used depends on the regulator is: injection of vehicle, changing a course according to the position of the deposit compared to the position of the incident, etc.

\section{2) Analyze of the situation (multi-agent approach)}

The delay estimated by vehicle $\mathrm{V} 2$ is of $7 \mathrm{~min}$. Thus instead of arriving at 10:05, it will arrive at 10:12 in the stop A4 and the delay tolerated is of $2 \mathrm{~min}$. This delay creates not only one irregularity in the intervals but also a risk of a missed connection. The following tables present the table of theoretical and disturbed Timetable.

Table 3

Theoretical TimeTable (Line B and Line 34)

\begin{tabular}{cccrc}
\hline \multicolumn{5}{c}{ Line B (L1) } \\
\hline & $A_{2}^{1}$ & \multicolumn{1}{c}{$A_{3}^{1}$} & \multicolumn{1}{c}{$A_{4}^{1}$} & \multicolumn{1}{c}{$A_{5}^{1}$} \\
\hline$V_{1}^{1}$ & $9: 25$ & $9: 35$ & $9: 45$ & $10: 05$ \\
$V_{2}^{1}$ & $9: 35$ & $9: 45$ & $\mathbf{1 0 : 0 5}$ & $\mathbf{1 0}: \mathbf{1 5}$ \\
$V_{3}^{1}$ & $9: 45$ & $10: 05$ & $\mathbf{1 0 : 1 5}$ & $\mathbf{1 0}: \mathbf{2 5}$ \\
\hline
\end{tabular}

\begin{tabular}{cccrc}
\hline \multicolumn{5}{c}{ Line 34(L2) } \\
\hline & $A_{2}^{2}$ & $A_{3}^{2}$ & \multicolumn{1}{c}{$A_{4}^{2}$} & \multicolumn{1}{c}{$A_{5}^{2}$} \\
\hline$V_{1}^{2}$ & $9: 27$ & $9: 37$ & $9: 47$ & $10: 07$ \\
$V_{2}^{2}$ & $9: 37$ & $9: 47$ & $\mathbf{1 0 : 0 7}$ & $\mathbf{1 0 : 1 7}$ \\
$V_{3}^{2}$ & $9: 47$ & $9: 57$ & $\mathbf{1 0 : 1 7}$ & $\mathbf{1 0 : 2 7}$ \\
\hline
\end{tabular}

Table 4

Disturbed TimeTable reconfigured by the agent INCIDENT (Line B and Line 34)

\begin{tabular}{ccrrc}
\hline & $A_{2}^{1}$ & \multicolumn{1}{c}{$A_{3}^{1}$} & \multicolumn{1}{c}{$A_{4}^{1}$} & \multicolumn{1}{c}{$A_{5}^{1}$} \\
\hline$V_{1}^{1}$ & $9: 25$ & $9: 35$ & $9: 45$ & $10: 05$ \\
$V_{2}^{1}$ & $9: 35$ & $9: 45$ & $\mathbf{1 0 : 1 2}$ & $\mathbf{1 0 : 2 2}$ \\
$V_{3}^{1}$ & $9: 45$ & $10: 05$ & $\mathbf{1 0 : 2 2}$ & $\mathbf{1 0 : 3 2}$ \\
\hline
\end{tabular}

\begin{tabular}{cccrc}
\hline & $A_{2}^{2}$ & $A_{3}^{2}$ & \multicolumn{1}{c}{$A_{4}^{2}$} & \multicolumn{1}{c}{$A_{5}^{2}$} \\
\hline$V_{1}^{2}$ & $9: 27$ & $9: 37$ & $9: 47$ & $10: 07$ \\
$V_{2}^{2}$ & $9: 37$ & $9: 47$ & $\mathbf{1 0 : 1 4}$ & $\mathbf{1 0 : 2 4}$ \\
$V_{3}^{2}$ & $9: 47$ & $9: 57$ & $\mathbf{1 0 : 2 4}$ & $\mathbf{1 0 : 3 4}$ \\
\hline
\end{tabular}




\section{3) Evaluation of the consequence of the disturbance}

Following a delay of 7 min the passengers of vehicle V2 of the line L1 " $V_{2}^{1}$ " whose take a vehicle of the line L2 will miss the connection of 10:07 and must wait consequently, the connection of 10:17 min, what causes a total delay of 12 min in their course.

Being given that the vehicle, which follows the late vehicle, arrives at the stop at 10:15 min. In addition, the passengers of the vehicle " $V_{2}^{1}$ " those from " $V_{3}^{1}$ " must also take the vehicle of line 2 , which involves a very significant momentary flow and a train of bus (successively vehicles with no respect of intervals).

\section{4) Operation of the multi-agent module of TRSS}

The system according to the data of the TTT and those of the DTT evaluate the importance of the disturbance. Being given that the system functions in real time, therefore the importance of the disturbance decreases according to the evolution of the network in time. The system proposes a first solution, which will be improved with time until arriving at a satisfactory solution for the regulator. At this time the regulator stops research.

\section{5) Solutions suggested by the multi-agent system}

In this case we interrupted the anytime algorithm three time with 10 seconds regular interval. We obtain the following responses (Table 5).

Table 5

Suggested solutions by the multi-agent module

\begin{tabular}{|c|c|c|c|}
\hline $\begin{array}{l}\text { Time } \\
\text { before }\end{array}$ & $\begin{array}{l}N^{\circ} \\
\text { Solution } \\
\text { and title }\end{array}$ & Proposition & $\begin{array}{l}\text { Proposed } \\
\text { Evaluation } \\
\text { by TRSS }\end{array}$ \\
\hline $\begin{array}{l}\mathbf{t} 1 \\
20 \mathrm{sec}\end{array}$ & 1 & $\begin{array}{l}\text { - change the schedules of passage of the vehicles } \\
\text { according to the delay, } \\
\text { - apply the new one TTT = DTT. }\end{array}$ & $\begin{array}{l}-\mathrm{AT}=100 \% \\
-\mathrm{TT}=100 \% \text { assured } \\
\text { - } \mathrm{SP}=50 \% \text { because the } \\
\text { passengers at stops are } \\
\text { not dealt with. }\end{array}$ \\
\hline $\begin{array}{l}\mathbf{t} 2 \\
30 \mathrm{sec}\end{array}$ & $\begin{array}{l}\quad 2 \\
\text { Handing-over } \\
\text { at hour by re- } \\
\text { serve (vehicle) } \\
\text { and available } \\
\text { (conductor) }\end{array}$ & $\begin{array}{l}\text { - use the bus of the standard type (reserve) in the } \\
\text { deposit, } \\
\text { - create a new course in line L } 2 \text { for the passengers } \\
\text { on standby in the connection, } \\
\text { - update TTT for the insertion of the new course. }\end{array}$ & $\begin{array}{l}-\mathrm{AT}=100 \% \\
-\mathrm{TD}: \text { not concerned } \\
-\mathrm{TT}=100 \% \\
-\mathrm{SP}=100 \%\end{array}$ \\
\hline $\begin{array}{l}\mathbf{t 3} \\
40 \mathrm{sec}\end{array}$ & $\begin{array}{l}\quad 3 \\
\text { Regulation on } \\
\text { line }\end{array}$ & $\begin{array}{l}\text { - exploit the time of beat to the stops to reabsorb the } \\
\text { delay caused by this disturbance, } \\
\text { - prevent the vehicle of the line L2 to increase its } \\
\text { speed in order to arrive earlier, } \\
\text { - prevent the vehicles which follow the late vehicles } \\
\text { of line L1 to slow down its speed in order to avoid } \\
\text { a train of bus, } \\
\text { - create a new TTT. }\end{array}$ & $\begin{array}{l}-\mathrm{AT}=90 \% \\
-\mathrm{TD}: \text { not concerned } \\
-\mathrm{TT}=0 \% \\
-\mathrm{SP}=70 \%\end{array}$ \\
\hline
\end{tabular}

Remarks: We notice that a satisfaction passenger is proportional to the reduction in the regularity of the means of transport. The more waiting increases and the less satisfied the customers are. 


\section{Discussion}

The regulation function can be defined as a process functioning in real time in order to supervise the urban transportation network, and to satisfy the request as well as possible. That consists in having a view as precise as possible of the situation and results in obtaining a maximum of relevant information, owing to the fact that certain decisions must be made in urgency. The information will be disposed to the regulator in little time.

The identification of the behavior of regulator and the adaptation of a cognitive engineering model, enabled us to set up of a convivial environment of supervision. The interfaces suggested to the regulator were built on the basis of an evaluation model SADT/Petri (Kolski, 2001). Then, as we suggest, our interesting in the decision phase, led to propose the interaction between different approach: a mathematical one and two approaches resulting from the artificial intelligence.

The CBR model will be used in our application, to determine solutions to familiar incidents. The regulator being the master can accept or refuse the proposals made by this module.

Within the framework of the regulation of the urban network of Oran City, the consultation of the incident sheets carried out by the services of the maintenance and regulation, raises a thousands of incidents per year, whose majority are similar, as much on the context that on the strategies applied to solve them. From this point of view, the choice of this model is largely justified because it reduces the charge of the regulator of various disturbances that are posted on the level of its supervision tool. According to this first approach, the second module permits to the regulator to solve disturbances according to mathematical models when no proposal come from the CBR module or when the regulator is doesn't interested by the suggested solution.

Nevertheless, the mathematical model, resulting from the general concepts of control and the automatically operation, are theoretically well founded and rigorously established. Nevertheless, they are based on models, which do not illustrate, as it should be the reality of the phenomena in progress, where is a shift between the theoretical approaches and the practical installations.

The various analytical equations of the models are based on starting assumptions, often simplifying and reducing compared to the real situations. Moreover, the will to consider more realistic assumptions generally brings to models with great complexity for which it is difficult to determine the optimal solutions and to control the stability. Where all interest to propose a generalized model of regulation for bimodal (buses and trams) collective urban traffic network with a distributed architecture. In this architecture we assigned to each agent specific roles where the cooperation between these agents makes it possible to set up a innovating process of regulation integrating an anytime algorithm into the level of the agent in charge of the active regulation of the network.

However, within the framework of the computerized decision-making systems, an incomplete or partial result obtained in times and often preferable to a precise and complete result obtained except time and thus not exploitable. The approach anytime seems very promising for the taking into account of such situations. It is the reason for which we think that it would be relevant to integrate this technique in the design of our system. 
There are some works in the field of multi-agent destined to urban transportation network, but in the majority the existing approaches, neglects the taking into account of the real time for the regulation of an urban system and the role (know-how) of the regulator. The work of Balbo (2000) concerning the "ESCA" system, proposes a multiagent architecture for the regulation in inter-station, this work consists of the information management relating to a disturbance in order to bring an assistance to the regulator.

Laichour (2002), for its system "SARC", only proposes a multi-agent architecture for the regulation of the urban network system to the nodes of connections. Its work consists in ensuring the correct operation of the connection and to propose solutions to the regulator in the event of connection missed by the means of a simulation of day before. It is not thought that the regulator has time to make simulations before proposing a solution. The prototype SMAAD (Fayech, 2003) proposes a cooperation between a multi-agent approach and a genetic algorithm, for the regulation of a multimodal urban transportation network. This approach enabled him to improve the solutions suggested for the regulator, and to approach towards the optimal solution, but in not exploitable times for the regulator.

Others work are already made, Adamski (1998) presents a dynamic model being based on the optimal order for the regulation, with a matrix representation of the various variables of state (deviations of the theoretical schedules), of control and disturbance. But, this model does not take account the correspondences. The approaches resulting from the general concepts of control and the operation automatically are theoretically well founded and rigorously established. Nevertheless, they are based on assumptions of modeling which are often simplifying and reducing. Moreover, they relate to regulation with simulation detailed in station without worrying about the state of an oar or a vehicle between two stations.

In addition, the regulation is often regarded as a planning in real time. It is then about a regrouping of the vehicles according to the real conditions of operating. Li (1991) developed stochastic linear programming a model for the regulation of a line of bus. It approach is based on the modification of the races assigned to the vehicles thanks to the improvement of scenarios filed as a preliminary and already lived, by taking account of flows of the passengers. On the other hand, it does not deal with the problem of the correspondence.

Yan (1997) proposes a heuristic based on the relaxation of Lagrange in order to manage the air traffic in the event of disturbances. It presents a modeling according to the time and the space of the scheduling of the planes in the shape of a graph. This graph shows the sequencing of the tasks carried out by the planes.

Huissman (2001) developed an approach of dynamic scheduling resulting from the dynamic programming with relaxation. Its goal is to assign the various races to the vehicles for a fixed horizon. The creation of the schedules is then made almost in real time if the horizon is rather reduced. Huissman (2001) considers initially the problem of a static scheduling, which it generalizes in a dynamic problem by changing the parameters of time and the horizon. Also, it generalizes the problem of scheduling to only one deposit with a problem multi-deposit by reiterating the application of the approach to each de- 
posit until obtaining the optimal solution. In addition, the flow of the passengers and the problems of correspondence are not considered.

There are nevertheless certain forms of knowledge which are sometimes essential and which are not represented in a formal way in the majority of the models, like the knowhow of the experts. Thus, Issai (2001) presents a predictive approach and another reactive of scheduling of the trains which takes account of the expertise and knowledge of the human operators. The two approaches are compared according to the combined use of the data and knowledge and also according to levels' of uncertainty. The objective is to avoid and solve the conflicts resulting from the simultaneous occupation of the ways.

Aloulou (1999) presented a genetic approach of regulation of a line of bus by optimizing the criteria of punctuality and regularity. Its objective is to provide to the regulator simple decisions related to the modification of the schedules in order to reabsorb a delay caused by a disturbed bus.

Put aside the disadvantages quoted previously, the existing approaches of regulation do not treat the multimodal case of the urban transportation system. The majority of them limits the degree of intervention of the regulator and does not relate to the regulation in the case of the appearance of several incidents at the same time. Moreover, the correspondences are often treated by specific approaches which do not consider the other criteria of punctuality and regularity.

\section{Conclusion}

The regulation of the urban transportation system requires a complex process for which a computerized decision-making system must bring to the regulator information and the relevant tools for evaluation. We presented a supervisor tool that support a decision support system for regulation of disturbances in an urban transportation networks. The TRSS is based on a model of the decision-making process of the regulator resulting from cognitive engineering. This TRSS includes classical artificial intelligence approach represented by a CBR module that simplifies the task of regulator particularly when a familiar disturbance occurs. Also, it includes a regulation module based on mathematical models that permits to the regulator to resort to standard algorithms of the regulation. Finally, the TRSS integrate a distributed artificial intelligence approach represented by a multi-agent decision module that provides the regulators with relevant decisions to undertake in case of disturbances. This system relies on the data supplied by the automatic Vehicle Monitoring system or manually entry by the regulator. The considered multi-agent system includes an anytime algorithm that proposes partial solution to dysfunction that became precise in time. Moreover, in these systems, a partial or incomplete results obtained in real time are often preferred, because more useful for the decision-making than of the complete and precise results obtained late.

The exploiting of network validated the model of decision and the functional model. The implementation of the system is in hand which will be tested in simulation then on the Transvilles (City of Valenciennes) network and in the Oran City Future bimodal Network. 
Furthermore, this system can be also used for training and learning objectives. That is, the regulators can test, off-line, the impact of different combinations of decisions on several disturbance scenarios.

\section{References}

Aamodt, A. (1995). Knowledge acquisition and learning by experience - the role of case - specific knowledge. In Machine Learning and Knowledge Acquisition, Integrated Approach. Academic Press, Boston, Massachussetts. pp. 197-245.

Adamski, A., A. Turnau (1998). Simulation support tool for real time dispatching control in public transport. Transportation Research A, 32(2), 73-87.

Aloulou, M.A. (1999). Application des Algorithmes Génétiques à la Régulation du Trafic de Bus. DEA report en informatique industrielle. University of Lille.

Balbo, F. (2000). ESAC: un Modèle d'Interaction Multi-Agent Utilisant l'Environnement Comme Support Actif de Communication: Application à la Gestion des Transports Urbains. Ph.D. Thesis, University of Paris IX Dauphine.

Borne, P., B. Fayech, S. Hammadi, S. Maouche (2002). Decision Support System for Urban Transportation Networks. SMC C02-MS-005.

Bouamrane, K., T. Bonte, M. Sevaux, C. Tahon (2005). SART: un système d'aide à la décision pour la régulation d'un réseau de transport bimodal. In Méthodologies et Heuristiques pour l'Optimisation des Systèmes Industriels MHOSI'2005, Hamammet-Tunisie, 24-26 Avril. pp. 187-192.

Bouamrane, K., N. Benyetto, B. Beldjilali (2004). Urban transport bimodal network management using a multiagents system approach. In International Conference on Telecomputing and Information Technology. ICTITIEEE, Amman-Jordan.

Boumane, A. (2005). Application d'une méthodologie d'identification des compétences requises à l'activité de régulation d'un réseau de transport urbain. In Performance et Nouvelles Technologies en Maintenance PENTOM2005, Marrakech (Morocco), 18-20 Avril.

Bunke, H., B.T. Messmer (1994). Similarity measures for structured representations. In S. Wess, K.D. Althoff and M.M. Richter (Eds.), Proceeding of the First European Workshop "Topics in case-Based Reasoning" EWCBR'94, Kaiserslautern, Springer Verlag, Berlin. pp. 106-118.

Burstein, M.H. (1989). Analogy vs CBR: the purpose of mapping. In Proceedings of the Second Case Based Reasoning Workshop, Pensacola Beach, Floride. DARPA, Morgan Kauffman.

CERTU (1997). Evaluation des transports en commun en site propre: Indicateurs transport pour l'analyse et le suivi des opérations; Centre d'études sur les réseaux, les transports, l'urbanisme et constructions publiques, Novembre 1997.

Cure, C., B. Foraste (1984). Systèmes d'aide à l'exploitation et algorithmes de régulation. Recherche Transport Sécurité, July 1984.

Conceico, S.V., C.M. Silvestre (1996). Implémentation d'un système mixte de la gestion de production de production. In Actes du 5ème Congrés Interbnational de génie Industriel, tome 1. pp. 131-135.

Duvallet, C., B. Sadeg (2001). Concevoir un système d'aide à la décision basé sur un système multi-agent anytime, 2ème soumission à JFIADSMA'2001.

Eschnauer, H., J. Koski, A. Osyczka (1990). Multicriteria Design Optimization: Procedures and Applications. Springer-Verlag, New York.

Fayech, B., S. Hammadi, S. Maouche, P. Borne (2002). Approche cooperative pour la régulation d'un réseau de transport multimodal. In Congrés International Francophone d'Automatique, CIFA 2002, Nantes, France. pp. 177-182.

Fayech, B., S. Maouche, S. Hammadi, P. Borne (2002). Multi-agent decision-support system for an urban transportation network. In World Automation Congress 2002, Florida, USA.

Fayech, B. (2003). Régulation des Réseaux de Transport Multimodal: Systèmes Multi-agent et Algorithmes Évolutionnistes. Ph.D. Thesis, University of Lille.

Goonatilake, S., J.A. Campbell, N. Ahmad (1994). Genetic fuzzy systems for financial decision making. In Proc. IEEE/Nagoya-University World Wide Wisepersons, Selected papers. LNAI 1011, Springer-Verlag, Berlin. pp. 202-223. 
Gruer, P.V., H.A. Koukam (2001). Multi-agent approach to modeling and simulation of urban transportation systems. In Proceedings of 2001 IEEE SMC Conferences, Tucson, Arizona, USA. pp. 2499-2504.

Hoc, J.M. (1996). Supervision et Contrôle de Processus, la Cognition en Situation Dynamique. PUG Grenoble, France.

Huissman, D., R. Freling, A.P.M. Wagelmans (2001). A Dynamic Approach to Vehicle Scheduling. Econometric Institute, Erasmus University Rotterdam, Netherlands Report E12001-17.

Issai, M.T., N.P. Cassaigne (2001). Predictive and reactive approaches to the train-scheduling problem: a knowledge management perspective. IEEE Transactions on SMC, Part C, Applications and Reviews, 31(4), 476484.

Kacem, I., S. Hammadi, P. Borne (2002). Pareto-optimality approach for flexible job-shop scheduling problems: hybridization of genetic Algorithms with fuzzy logic. Journal of Mathematics and Computer in Simulation, Elseiver Science, 245-276.

Kolski, C. (2001). Analyse et conception de l'IHM: Interactions homme-machine pour les SI, Tome 1, Hermès Sciences Edition.

Laichour, H. (2002). Modélisation Multi-agent et aide à la décision: Application à la Régulation des Correspondances dans les Réseaux de Transport Urbain. Ph.D. thesis, University of Lille.

Leplat, J. (1997). Regards sur l'activité en situation de travail, contribution à la psychologie ergonomiques, PUF.

Meystel, I.A. (2001). The tools of intelligence: are we smart enough to handle them? In Proceedings of IFDICON'2001, European Workshop on Intelligent Forecasting, Diagnosis and Control, Santorini, GREECE. pp. 2-4.

Mille, A., A. Napoli (1997). Aspects du raisonnement à partir de cas. 6ème journée nationale PRC-GDR IA'97.

Mignot, $\mathrm{H}$. Sensibilité au contexte lors de l'évaluation de similarité en raisonnement à partir de cas. In Laboratoire de recherche en informatique, Paris, University of Paris-Sud. pp. 175.

Millot, P. (1988). Supervision des Procédés Automatisés et Ergonomie. Hermes Edt, Paris, France.

Pasquier, L. (2000). Modélisation de raisonnements tenus en contexte et application aux agents d'aide à la gestion d'incidents de SART. Research Report LIP6 2000/010.

Semurval, (2004). Document Semurval sur les actions de la régulation, reçu le 29 janvier 2004.

Sheridan, T. (1985). Forty-five years of man-machine system: history and trends. In 2nd IFAC on analysis, Design and Evaluation of man-Machine Systems, Varèse, Italie.

Sheridan, T., R. Ferrel (1994). Man Machine Systems. Cambridge, MA: MIT.

Soulhi, A. (2000). Contribution de l'intelligence Artificielle à l'aide à la décision dans la gestion des systèmes de transport urbain collectif. Ph.D. thesis, University of Lille.

Staroswiecki, M., A.L. Gehin (1998). Analysis of systems reconfigurability using generic components models. In International Conférence on Control'98. Swansea, Royaume-Uni.

Thangiah, S.R. (1995). Vehicle routing with time windows using genetic algorithms. Artificial Intelligence and robotics Laboratory, Slippery Rock university USA. In 1. Chambers (Ed.), Applications Handbook of Genetic Algorithms: New Frontiers, vol. II, CRC Press. pp. 253-277.

VTP Vision (2005). http://www.english.ptv.de/cgi-bin/traffic/traf_visum.pl

Yan, S., Y.P. Tu (1997). Multifeet routing and multistop flight scheduling for schedule perturbation. European Journal of Operational Research, 103(1), 155-169.

Zhu, K.Q. (2000). A new genetic algorithm for VRPTW. Journal of Combinatorial Optimization, April 2000. http://citeseer.nj.ncc.com/311264.html. 
K. Bouamrane received the engineer degree in computer science from Department of Computer Science of Oran Algeria, and the master of science degree in the same department, in 1991 and 1996 respectively. He is currently a PhD candidate in the LAMIH/SP Laboratory at the University of Valenciennes France and Computer Science Department at the University of Oran Algeria. His research interests include decision support system artificial intelligence (experts systems), distributed database, and automated production systems.

C.Tahon received the $\mathrm{PhD}$ degree in computer science from Valenciennes University, France, in 1992. He is a professor in the Computer Science Department at the University of Valenciennes. His research interests are enginnering of information system, chain supply, decision support system, and production system.

M. Sevaux received the $\mathrm{PhD}$ degree in computer science from Ecole des Mines de Nantes, France, in 1998. He is a professor in the Computer Science Department at The University of Valenciennes. His research interests are operational research, linear programming, and genetic algorithm.

B. Beldjilali received the $\mathrm{PhD}$ degree in computer science from University of Oran $\mathrm{Al}$ geria, in 1996. He is a professor in the Computer Science Department at the University of Oran. His research interests include formal specifications, methodologies of specification, knowledge management, databases. 


\title{
Klasikini ir daugelio agentu būdus apjungianti sprendimu prièmimo sistema dvimodalio miesto transporto tinklo reguliavimui
}

\author{
Karim BOUAMRANE, Christian TAHON, Marc SEVAUX, Bouziane BELDJILALI
}

Susisiekimo imonė dabar susiduria su pagrindine problema, kaip užtikrinti aukštos kokybės aptarnavimą, kai vartotoju reikalavimai nuolat auga, o konkurencija vis stiprèja. Taigi, užtikrinant eismo reguliarumą būtina nustatyti atsitiktinius trukdžius, kurie veikia susisiekimo sistemą ir panaikinti arba sumažinti jų įtaką eismui.

Šiame straipsnyje pristatoma sprendimu paramos sistema ERPS (Eismo Reguliavimo Paramos Sistema). ERPS yra skirta miesto susisiekimo sistemu reguliavimui. ERPS (tramvajus ir autobusas) paremta nuolatiniu operatoriaus sprendimų prièmimo procesu. Ji aprūpina operatorių informacija, kuri reikalinga nustatyti trukdžius ir įvertinti galimą pataisą, kurią būtina įvykdyti pagal pasirinktą reguliavimo strategija.

Pirmoje straipsnio dalyje pateiktas sprendimu prièmimo modelis su kuriuo dirba autoriai. Antroje dalyje aptariamas sprendimu paramos sistemos modelio veikimas.

Sprendiniu paramos sistema ir jos charakteristikos aprašomos trečioje dalyje. Ketvirtoje dalyje pristatomos ERPS sprendimu prièmimo priežiūros priemonès. Penktoje pateikti šios sistemos įvertinimo kriterijai, o šešta dalis skirta rezultatų pristatymui. 